\title{
Capabilities of Nasal Videoendoscopy in Diagnostics of Pharyngeal Tonsit Condition in Children with Bronchial Asthma
}

DOI: $1017691 / \mathrm{stm} 2016.8 .3 .15$

Received April 14, 2015

S.V. Krasilnikova, Otolaryngologist ${ }^{1}$;

T. Eliseeva, MD, PhD, Associate Professor, Department of Children Diseases;

A.V. Shakhov, MD, DSc, Professor, Eye and ENT Diseases Department2;

N.A. Geppe, MD, DSc, Professor, Head of the Department of Children Diseases ${ }^{3}$

1"Alexandria", Multi-Field Clinic of Nizhny Novgorod State Medical Academy, 65/1 Osharskaya St., Nizhny Novgorod, 603057, Russian Federation;

2Nizhny Novgorod State Medical Academy, 10/1 Minin and Pozharsky Square, Nizhny Novgorod, 603005,

Russian Federation;

3.M. Sechenov First Moscow State Medical University, 8, Bld. 2 Trubetskaya St., Moscow, 119991,

Russian Federation

The aim of the investigation was to assess nasal videoendoscopy capabilities in the diagnostics of pharyngeal tonsil condition in children with atopic bronchial asthma (BA).

Materials and Methods. We studied the condition of pharyngeal tonsil in 116 patients aged from 3 to 17 years (mean age $9.7 \pm 4.3$ years), with atopic BA of various severity complaining of nasal breathing problems, using rigid rhinoscopes (Karl Storz, Germany), 2.7 and $4.0 \mathrm{~mm}$ in diameter, viewing angle being 0 and $30^{\circ}$, laryngoscope $90^{\circ}$ (Atmos, Germany), flexible nasopharyngoscope, $3.2 \mathrm{~mm}$, and video camera (Atmos, Germany). Control group involved 108 children comparable in age and gender, with complaints of nasal breathing disturbances, without BA.

Results. The application of nasal videoendoscopy enabled to find out the incidence of degree II-III hypertrophy of pharyngeal tonsil among children with BA at any age to be significantly higher than that in control group children (without BA). According to the present study, hypertrophy of pharyngeal tonsil contributes considerably in nasal obstruction formation in BA children: $86.1 \%$ preschool children, $74.2 \%$ primary school children, $45.8 \%$ senior school children, and $20 \%$ adolescents that should be taken into consideration when managing such patients.

Conclusion. Nasal videoendoscopy enables to eliminate diagnostic difficulties, and evaluate objectively the pharyngeal tonsil condition in patients with bronchial asthma of different age groups. The merit of nasal videoendoscopy in obtaining new data on the fact that hypertrophy of pharyngeal tonsil in general is more common in asthmatic patients than among children without asthma, and it should be taken into account in the management of such patients.

Key words: bronchial asthma; hypertrophy of pharyngeal tonsil; nasal videoendoscopy.

The state of pharyngeal tonsil is of particular interest in the study of the relationship of allergic diseases of the respiratory tract and pathologies of lymphoepithelial ring of pharynx [1]. In the norm, maximal development of lymphoid tissue occurs in children aged from 3 to 5 years, it is of physiological nature and due to determinate transient changes of the immune system peculiar to the age. As a rule, if there is no pathology, since $5-7$-year age, natural involution of pharyngeal tonsil starts [2]. Hypertrophy of pharyngeal tonsil (HPT) can develop in patients with upper respiratory infections, and according to some authors $[3,4]$ is also typical for patients with allergic diseases of the respiratory tract including bronchial asthma (BA).
Allergic inflammation, which is the pathological basis of BA, does not localize only in bronchial tree structures but also involves upper respiratory tract (URT) (single air passage - single disease) and MALT-system (Mucosa associated lymphoid tissue) associated with mucosae [5]. Retronasal direction of mucociliary clearance determines a key role of the pharyngeal tonsil as an inductive organ of URT mucosal immunity [6]. The main flow of antigens is delayed and caught, primarily, by epithelial structures of the pharyngeal tonsil. When interacting with viral microbial environment and respiratory allergens, pharyngeal tonsil functions as a barrier of mucosae, participates in mucosal immunity formation and the

For contacts: Tatyana I. Eliseeva, e-mail: eliseevati@ya.ru 
pathogenesis of inflammatory processes in the nasal cavity and paranasal sinuses [7].

Immune response of the pharyngeal tonsil is based structurally on hyperplasia of its lymphoid tissue [8]. Previously we showed [9] that HPT in BA patients can aggravate the symptoms of nasal obstruction typical for such patients due to frequent comorbidity of BA and allergic rhinitis.

There is a belief that in atopic children the risk of HPT development and hypertrophy degree is higher than in population in general $[3,10-12]$. The pathology of lymphoepithelial ring of pharynx in children with allergic diseases of the respiratory tract can aggravate the course of the underlying disease and is a complementary factor confounding life quality of patients [13]. The relationship of allergic rhinitis and HPT is proved by the reduction of lymphoepithelial structures of pharyngeal tonsil and alleviation of nasal obstruction during the administered topical steroids and antihistamines [14, 15].

Current studies have shown that inflammatory changes in the nasopharynx of patients with BA result in systemic effects due to systemic absorption of inflammatory mediators synthesized in URT [16]. Inflammatory postnatal secretion has an effect on an underlying airway. In literature there has being discussed the effect of nasobronchial reflex on BA course in patients with comorbid upper respiratory diseases. According to Undem et al., the irritation of nasal mucosa receptors can result in the shortness of breath, cough or bronchospasm in BA patients [17-19]. It indicates the need for thorough diagnosis and treatment of URT pathology in patients to provide a complete BA control.

Currently, true incidence of HPT and diseases associated with this component of lymphoepithelial ring of pharynx in children with BA has not been determined so far. This is also due to the fact that the diagnostics of pathological lymphoepithelial ring of pharynx is still a complex problem. And for this reason the description of pharyngeal tonsil condition is of particular complexity, since its imaging in standard otorhinolaryngological examination is impossible due to its specific topography. There are various recommendations on nasopharynx pathology diagnosis, such as lateral view of the neck, palpation of nasopharynx, posterior indirect rhinoscopy and video endoscopy. However, the informativity of each of the mentioned diagnostic techniques is certain to be insufficient [20].

To assess pharyngeal tonsil condition we chose nasal videoendoscopy as the most informative and rapid among the available current methods and not associated with radiation exposure.

The aim of the investigation was to assess nasal videoendoscopy capabilities in the diagnostics of pharyngeal tonsil condition in children with atopic bronchial asthma.

Materials and Methods. We studied the examination results of 116 patients with atopic BA of different severity combined with URT pathology aged from 3 to 17 years (mean age $9.7 \pm 4.3$ years); among them there were 87 boys and 29 girls. The following age groups were distinguished: preschool age (36 children, from 3 to 6 years); primary school age (35 children, from 7 to 11 years); grammar school age (24 children, from 12 to 14 years); adolescence (21 children, from 15 to 17 years). Control group included 108 children without BA with complaints of nose breathing problems comparable in age and gender (preschool age: 34 children; primary school age: 39 children; grammar school age: 20 children; and adolescence: 15 children).

BA diagnosis was verified in accordance with the National program recommendations "Bronchial asthma in children. Treatment strategy and prevention", and with consideration for the regulations of Global Strategy for Asthma Management and Prevention revised in 20112015 [21, 22]. Inclusion criteria were: the symptoms of acute respiratory infection and temperature rise.

The children were examined on the basis of City Children Clinical Hospital No.1, Nizhny Novgorod, and Multi-Field Clinic "Alexandria" of Nizhny Novgorod State Medical Academy. The examination included physical examination according to industry-specific medical standards, laboratory and instrumental diagnostic techniques, determination of respiratory function parameters, skin tests with nonbacterial allergens, determination of general and allergen-specific $\operatorname{lgE}$. When studying past history data and physical examination, we assessed BA severity and the disease control level according to GINA criteria and a short version of Asthma Control Questionnaire-5 (ACQ-5) judging by a case history or medical treatment records. The study complied with the declaration of Helsinki (adopted in June, 1964 (Helsinki, Finland) and revised in October, 2000 (Edinburg, Scotland)) and was approved by the Ethics Committee of I.M. Sechenov First Moscow State Medical University. All patients aged 15-17 years and the parents of children under 15 years gave their written informed consent in accordance with Federal Law "The Basic Law on the Health Protection of the Citizens of the Russian Federation" dated July, 22, 1993, No.54871.

When estimating URT pathology, the diagnoses were verified due to International Statistical Classification of Diseases and Related Health Problems [23], recommendations "Allergic Rhinitis and its Impact on Asthma [24], International Consensus Report on the diagnosis and management of rhinitis [25], European paper on rhinosinusitis and nasal polyps [26], classifications of the pathology of lymphoepithelial ring of pharynx [27, 28].

The diagnosis of allergic rhinitis was made based on the past history results, the assessment of clinical signs (nasal obstruction, pruritis, sneezing, rhinorrhea, and visual estimation data: rhinoscopy). Moreover, we assessed the color, tone, the presence of edema, 
hypertrophic changes of nasal mucosa, the presence and type of nasal discharges in a nasal passage.

In addition to standard otorhynolaryngological examination, URT study included video endoscopy of the nasal cavity and nasopharynx using the equipment and endoscopic photography. We applied rigid rhinoscopes Karl Storz (Germany), the angle of view being 0 and $30^{\circ}$, diameter 2.7 and $4.0 \mathrm{~mm}$; videolaryngoscopy was performed by laryngoscope $90^{\circ}$ (Atmos, Germany) and flexible nasopharyngoscope $3.2 \mathrm{~mm}$; video recording was made by a video camera (Atmos, Germany). Nasal videoendoscopic examination was performed after $2 \%$ lidocaine instillation on nasal mucosa and application anesthesia by $0.1 \%$ adrenaline hydrochloride solution and $10 \%$ lidocaine.

When examining nasopharynx, we estimated the pharyngeal tonsil size, the presence of inflammatory response of the tissue, the nature and amount of secretion of the tonsil surface. In addition, we assessed the eustachian tonsil, the areas of auditory tube orifices. The videoendoscopic findings were processed and archived using Adobe Photoshop.

Statistically, the findings were analyzed using the programs Statgraphics plus and Biostat. The data were represented as $M \pm m$, where $M$ is mean, and $m$ is standard deviation. Statistical differences of quantitative signs were assessed by Student t-test and ANOVA, and qualitative differences were estimated using $\chi^{2}$ test. The differences were considered significant if $p<0.05$.

Results and Discussion. Thorough examination of URT pathology in children with atopic BA of different severity, and their complaints of nasal breathing difficulties enabled to reveal different types of impairments, the nasal cavity alterations prevailing. All the examined children were diagnosed allergic rhinitis of different severity [29]. The nasal videoendoscopy applied enabled to assess the condition of nasal and nasopharyngeal structures, the pathological changes of

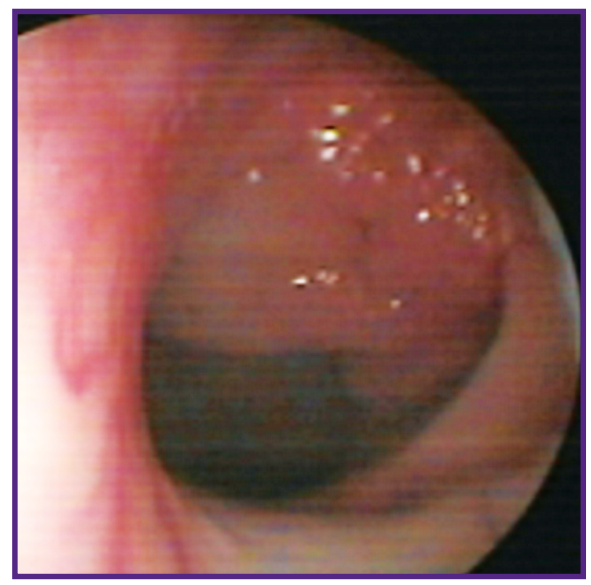

Figure 1. 6-year-old patient L. Nasal videoendoscopy fragment. Photo: the left choana view; adenoid tissue of pharyngeal tonsil is loose, closes $1 / 2$ of the choanal lumen
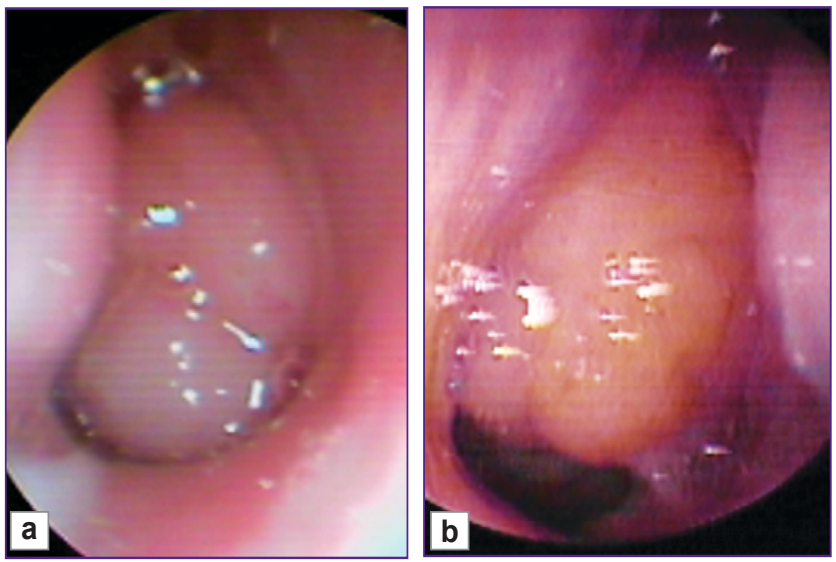

Figure 2. 6-year-old patient $\mathrm{V}(\mathrm{a})$ and 8-year-old patient $\mathrm{N}$. (b). Nasal videoendoscopy fragments. Photo: (a) the right view of choanal lumen; lymphoid tissue of the pharyngeal tonsil obturates the choanal lumen almost completely; (b) the left view of choanal lumen; the pharyngeal tonsil closes just over $2 / 3$ of the choanal lumen, adenoid vegetations overhang the orifices of the eustachian tubes, there is mucoserous discharge on the pharyngeal tonsil surface

lymphoid tissue and associated ORL diseases to higher accuracy and in an integrated manner.

Pharyngeal tonsil pathology was diagnosed in $62.0 \%(72 / 116)$ examined patients with atopic BA. No correlation of the pathology with BA severity was found $(F=0.91 ; p=0.34)$. According to nasal videoendoscopy, degree II HPT (the pharyngeal tonsil closed no less than $1 / 2$ of the choanal lumen (Figure 1)) was found in $29.3 \%$ children (34/116).

Adenoid vegetations of III degree were revealed in $32.7 \%$ patients $(38 / 116)$. In these patients HPT tissue closed the 2/3 of choanal lumen (Figure 2).

Thus, generally, adenoid hypertrophy revealed by nasal videoendoscopy was found in more than a half of the examined patients with $\mathrm{BA}$, and $32.7 \%$ children with BA appeared to have a significantly enlarged pharyngeal tonsil (degree III hypertrophy).

Since adenotonsillar hypertrophy has its age peculiarities, we used nasal videoendoscopy to study the prevalence of lymphoepithelial hypertrophy taking into consideration the age of BA patients. The patients with enlarged pharyngeal tonsil were found to be of different ages. The mean age of children with BA with normal sized pharyngeal tonsil was $12.50 \pm 4.14$ years. Generally, the children with HPT were significantly younger, their mean age being $8.1 \pm 3.6$ years $(F=36.27$; $p<0.0001)$. The mean age of patients with degree II HPT was $9.2 \pm 4.0$ years, the mean age of patients with degree III HPT being $7.2 \pm 2.9$ years $(F=19.8 ; p<0.0001)$.

Due to the revealed dependence of pharyngeal tonsil condition on children age we studied nasopharynx nasal videoendoscopy findings considering the age of $B A$ patients. 
Preschool age group. The patients of a young age group $(n=36)$ underwent nasal and nasopharyngeal endoscopy using, primarily, flexible optics. The following signs of allergic adenoiditis were found at the stage of allergic exacerbation: adenoid tissue of pale pink color, marked edema, flat sulci, the presence of mucoserous secretion on the pharyngeal tonsil surface (Figure 3).

According to the study findings, a part of patients with HPT against atopic BA among preschool children is $86.1 \%(31 / 36)$. 11 children were found to have II degree adenoid hypertrophy (Figure 4), and 20 children had III degree hypertrophy (Figure 5).

The main complaint of patients with both III and II degree of HPT was nasal breathing difficulty. In III

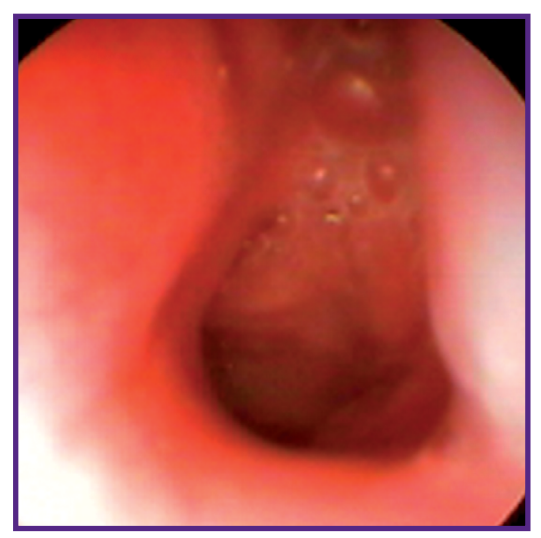

Figure 3. 4.5-year-old patient K. Nasal videoendoscopy fragment. Diagnosis: bronchial asthma, mild intermittent course; persistent allergic rhinitis, moderate severe, remitting exacerbation; allergic adenoiditis, degree I adenoids. Photo: the left view of choana: adenoid tissue of the tonsil closes $1 / 3$ of the choanal lumen, edema of the tonsil, on its surface there is foamy mucoserous discharge

Figure 5. 4.5-year-old patient M. Nasal videoendoscopy fragment. Diagnosis: hypertrophy of pharyngeal tonsil, III degree; persistent allergic rhinitis, moderate severe, with sensibility to epidermal and domestic allergens; controlled atopic bronchial asthma, moderate severe. Photo: (a) the left choana view: lymphoid tissue of the pharyngeal tonsil closes $2 / 3$ of the choanal lumen, the pharyngeal tonsil is edematous, on the tonsil surface there is mucous discharge; (b) the cloanal lumen is enlarged due to the pharyngeal tonsil reduced from III to II degree; 1/2 of the cloanal lumen is closed by lymphoid tissues degree, the nasal breathing problem was persistent due to mechanical obstruction of choanal lumen by hypertrophied tissue of the pharyngeal tonsil. Moreover, there was observed the adenoid tissue of the tonsil overhanging the orifices of auditory tubes, or their complete obstruction (See Figure 5). Otoscopically such patients showed retracted tympanal membranes due to the dysfunction of auditory tubes.

Primary school age group. These patients had their nose and nasopharynx examined using both flexible and rigid optics, the view angle being $0^{\circ}$. With age increment, the incidence of pharyngeal tonsil hypertrophy decreased up to $74.3 \%$ (26/35). Moreover, 13 patients were found to have enlarged pharyngeal tonsil up to II
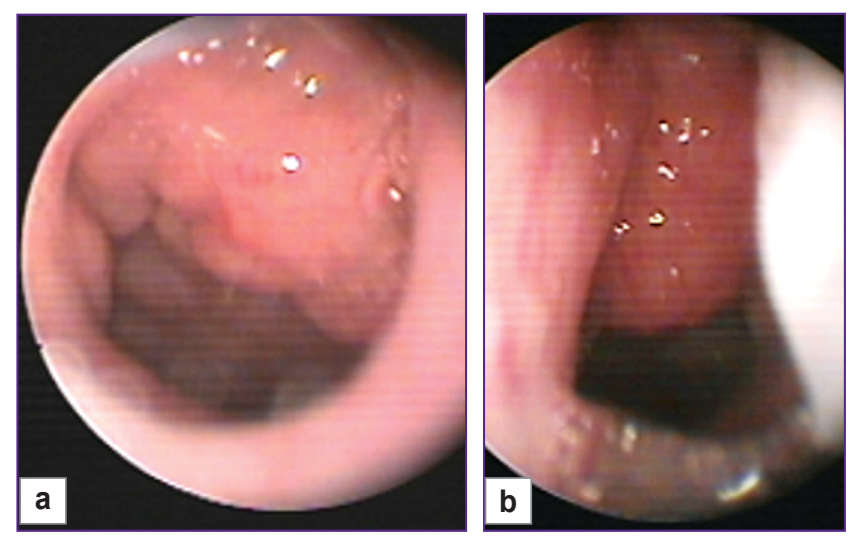

Figure 4. 4.4-year-old patient P. Nasal videoendoscopy fragments. Diagnosis: atopic bronchial asthma, mild persistent course, remitting exacerbation; persistent allergic rhinitis, moderate severe; allergic adenoiditis, degree II adenoids. Photo: the right (a) and left (b) choana view: lymphoid tissue of the pharyngeal tissue closes $1 / 2$ of the right choanal lumen (a), edematous pharyngeal tonsil, on its surface there is scanty serous discharge; pharyngeal tonsil obturates $1 / 2$ of the left choanal lumen (b)
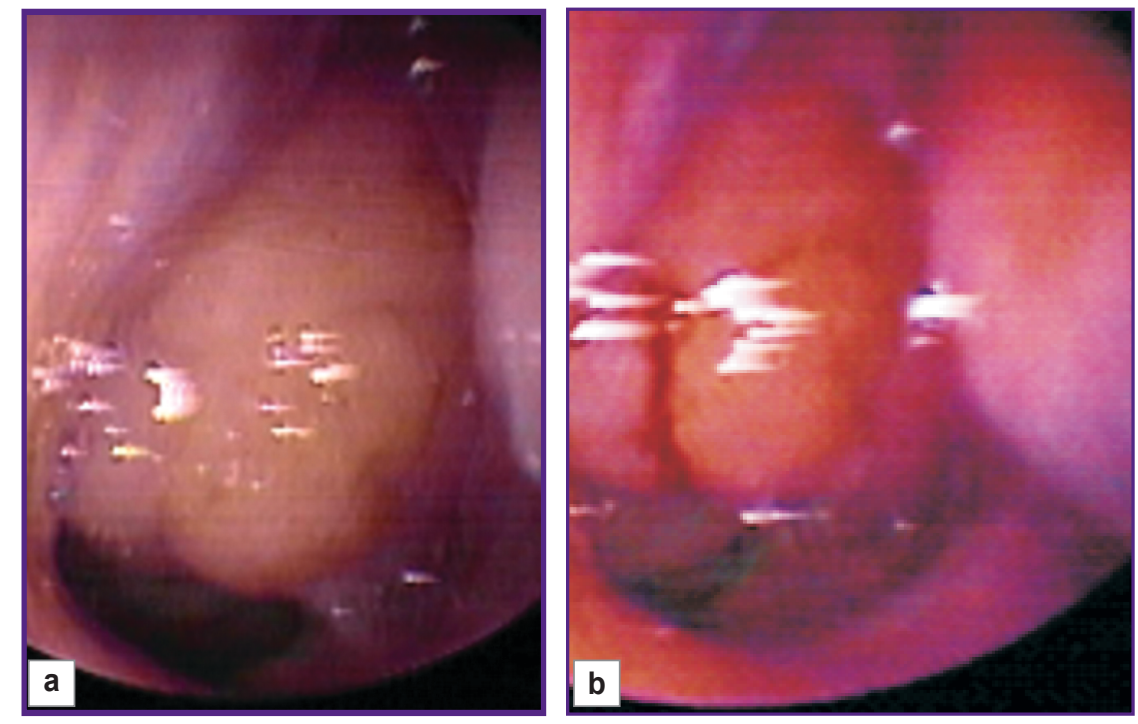
degree: adenoid tissue of the tonsil closed $1 / 2$ of choanal lumen (Figures 6,7).

Other 13 children with BA of this age group were diagnosed degree III adenoids (Figures 8, 9). These patients, in addition to nasal breathing problems, complained of cough, especially at the stage of allergic rhinitis exacerbation; the cough increasing when a patient was in the recumbent position (including nighttime), and BA children require differential approach

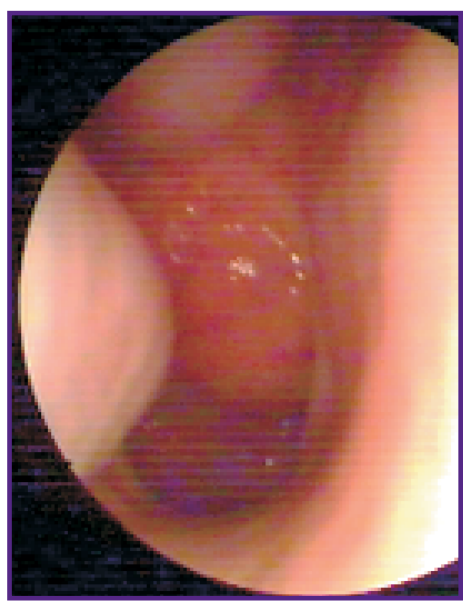

Figure 6. 10-year-old female patient $O$. Nasal videoendoscopy fragment. Diagnosis: controlled bronchial asthma, moderately severe; intermittent allergic rhinitis, moderately severe, remission; degree II adenoids; chronic compensated tonsillitis, remission. Photo: the right choana view: lymphoid tissue of the pharyngeal tonsil closes $1 / 2$ of the choanal lumen
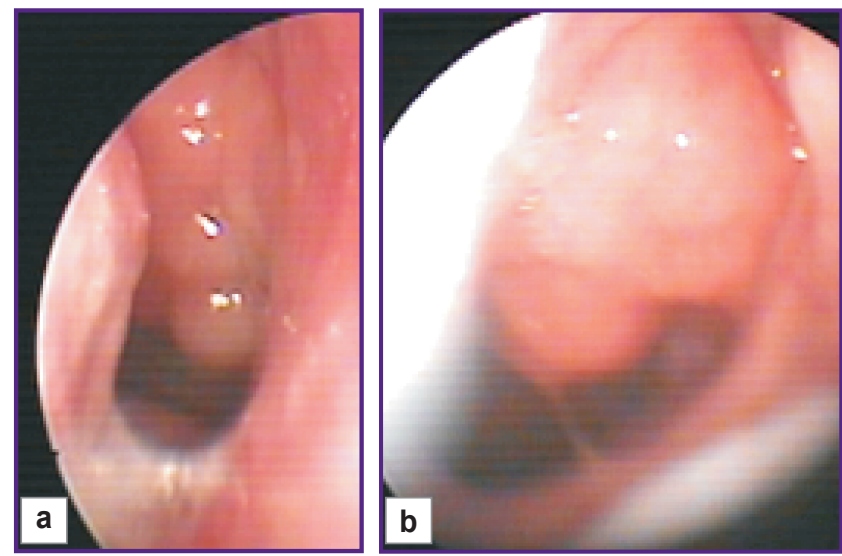

Figure 7. 9-year-old patient D. Nasal videoendoscopy fragments. Diagnosis: controlled atopic bronchial asthma, mild persistent course; persistent allergic rhinosinusitis, moderately severe; the nasal septum is deviated to the right; allergic adenoiditis, adenoids of II-III degree. Photo: the right (a) and left (b) choanal view: lymphoid tissue of the pharyngeal tonsil closes $2 / 3$ of the right choanal lumen (a), the pharyngeal tonsil is edematous; the pharyngeal tonsil obturates $1 / 2$ of the left choanal lumen (b), on the tonsil surface there is scanty serous discharge in cough diagnosis and therapy. Endoscopy in these patients showed the accumulation of mucous secretion in posterior inferior nasal meatus and on the pharyngeal tonsil surface visualized by nasal videoendoscopy.

Grammar school age group. Nasal videoendoscopy enabled to reveal HPT in most patients with BA in this age group: $45.8 \%(11 / 24)$ that differed from control children of the same age, among them HPT (degree II) was found in $10 \%$ patients only (2/20). Degree II HPT

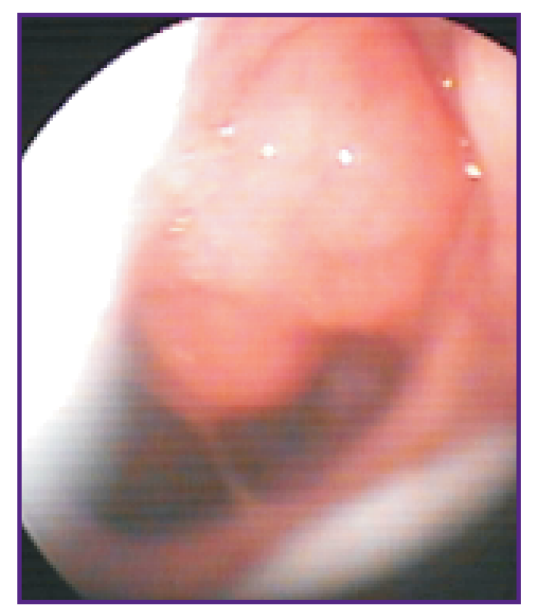

Figure 8. 8-year-old patient S. Nasal videoendoscopy fragment. Diagnosis: atopic persistent bronchial asthma, remitting exacerbation; persistent allergic rhinitis, severe course, exacerbation; allergic adenoiditis, degree III adenoids. Photo: the right choanal view: lymphoid tissue of the pharyngeal tonsil closes $2 / 3$ of the choanal lumen, the tonsil is edematous, on its surface there is mucous discharge
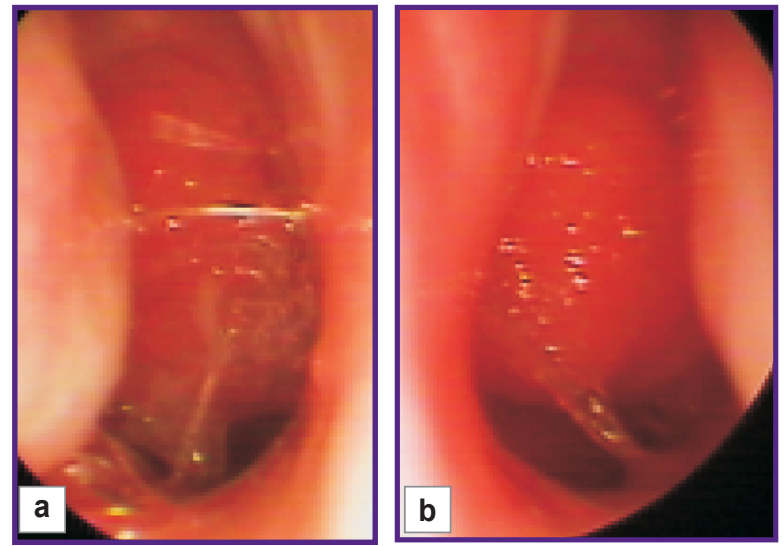

Figure 9. 8-year-old female patient A. Nasal videoendoscopy fragment. Diagnosis: atopic bronchial asthma, moderately severe, remitting exacerbation; persistent allergic rhinitis, moderately severe, exacerbation; allergic adenoiditis, adenoid vegetations of II-III degree. Photo: the right (a) and left (b) choanal view: lymphoid tissue of the pharyngeal tonsil closes $2 / 3$ of the right choanal lumen (a), the tonsil is edematous, on its surface there is mucoserous discharge; the pharyngeal tonsil obturates over $1 / 2$ of the left choanal lumen (b) 

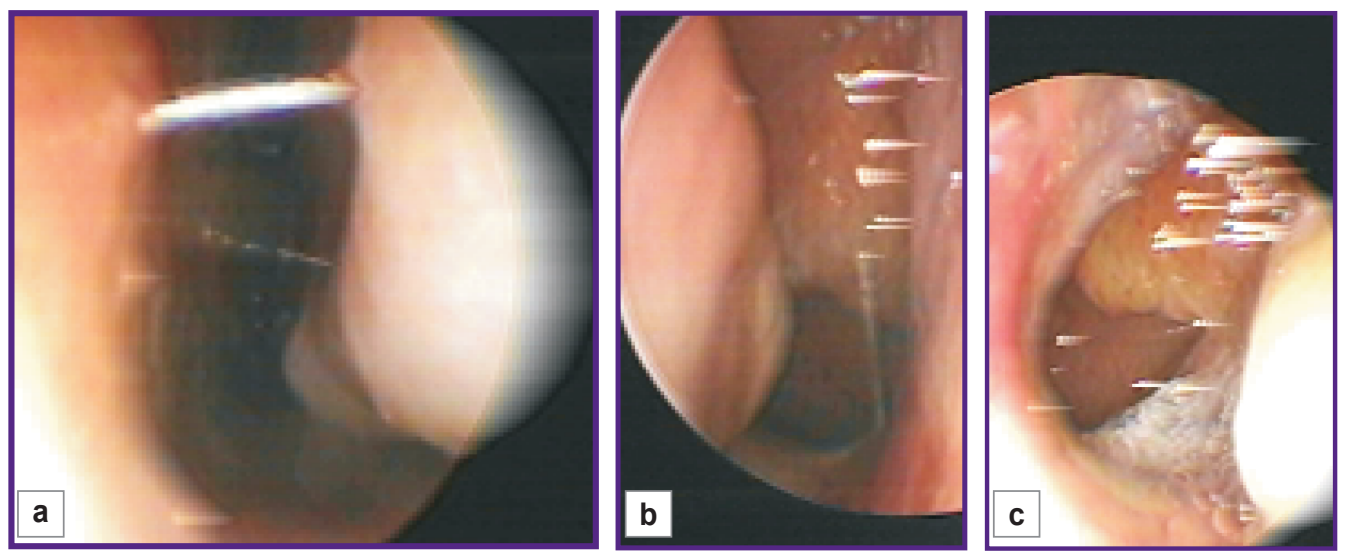

Figure 10. 13-year-old patient B. Nasal videoendoscopy fragments. Diagnosis: atopic bronchial asthma, mild persistent course, exacerbation; persistent allergic rhinitis, moderately severe, exacerbation; allergic adenoiditis, degree II adenoids. Photo: the left nasal cavity view: inferior nasal concha mucosa is pale, there is mucoserous discharge in the nasal passage lumen (a); loose and edematous tissue of the pharyngeal tonsil closing $1 / 2$ of the choanal lumen is visualized in the right (b) and left (c) choanal lumen. There is foamy mucoserous discharge on the tonsil surface and in the posterior part of inferior nasal meatus
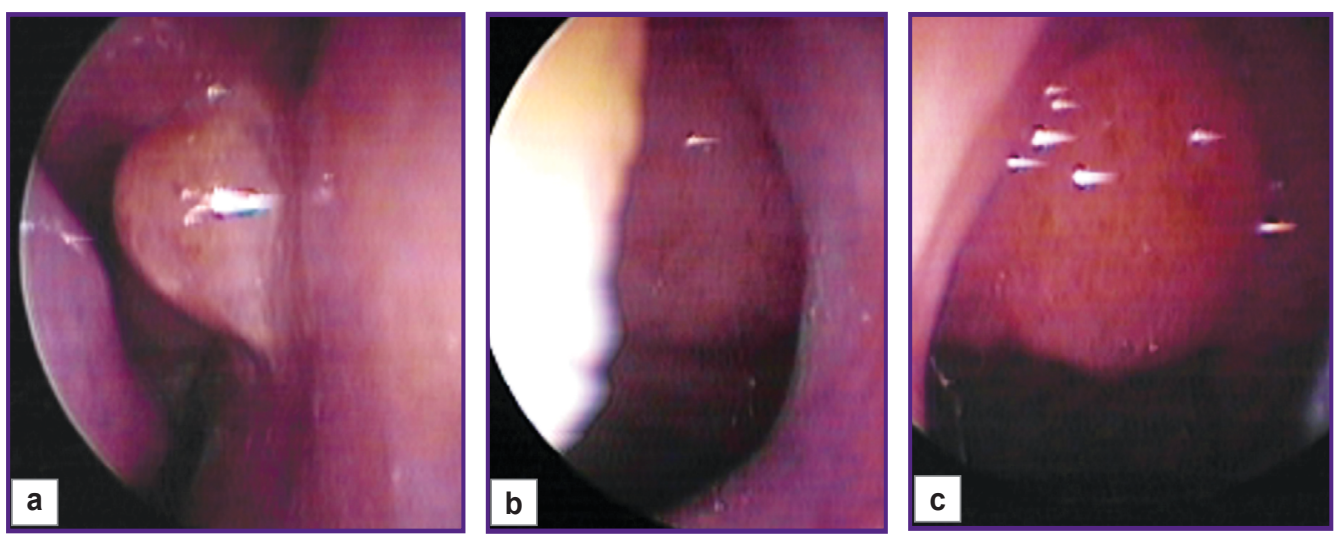

Figure 11. 12-year-old patient F. Nasal videoendoscopy fragments. Diagnosis: controlled atopic bronchial asthma, moderately severe; persistent perennial allergic rhinitis, severe course; hypertrophy of the mucosa of the anterior border of middle nasal concha, the right view; nasal septum deviation; degree II adenoids. Photo: the nasal cavity view: hypertrophy of the mucosa of the anterior border of middle nasal concha, the right view, the anterior border of middle nasal concha is in contact with the deviated cartilaginous part of the nasal septum (a); lymphoid tissue of the pharyngeal tonsil closing 1/2 of the choanal lumen is visualized in the right (b) and left (c) choanal lumen

was found among BA children of this age in 10 patients only (Figure 10).

III degree adenoids among these patients were revealed in $20.8 \%(5 / 24)$ patients with BA. Video endoscopic inspection enabled to diagnose hypertrophic processes in some patients not only in nasal-associated adenoid tissue but also in nasal mucosa (Figure 11 (a)). Similarly to the children of younger age groups, the patients of this age appeared to have obstruction of eustachian tubes in significantly enlarged pharyngeal tonsils (Figure 12).

Adolescents. Despite the fact that generally HPT was not typical for BA patients of adolescence age group $(n=21)$, nasal videoendoscopy enabled to reveal degree II HPT in $19 \%$ of them (4/21) (Figure 13). In addition, in some of these patients, video endoscopic inspection enabled to diagnose the presence of hypertrophic processes not only in nasal-associated adenoid tissue, but also in nasal mucosa (Figure 13 (a)). Nasal breathing problems in some adolescents worsened by impaired architectonics of the nasal cavity.

Thus, according to nasal videoendoscopy findings, HPT occurred more frequently in BA children of preschool and primary school age than among the children of older age $(z=5.1 ; p<0.0001)$. However, it should be mentioned that there was no pharyngeal tonsil reduction in a significant part of children with BA of senior age group and even among some adolescents.

Comparative nasal videoendoscopic characteristics of pharyngeal tonsil in patients with $B A$ and 

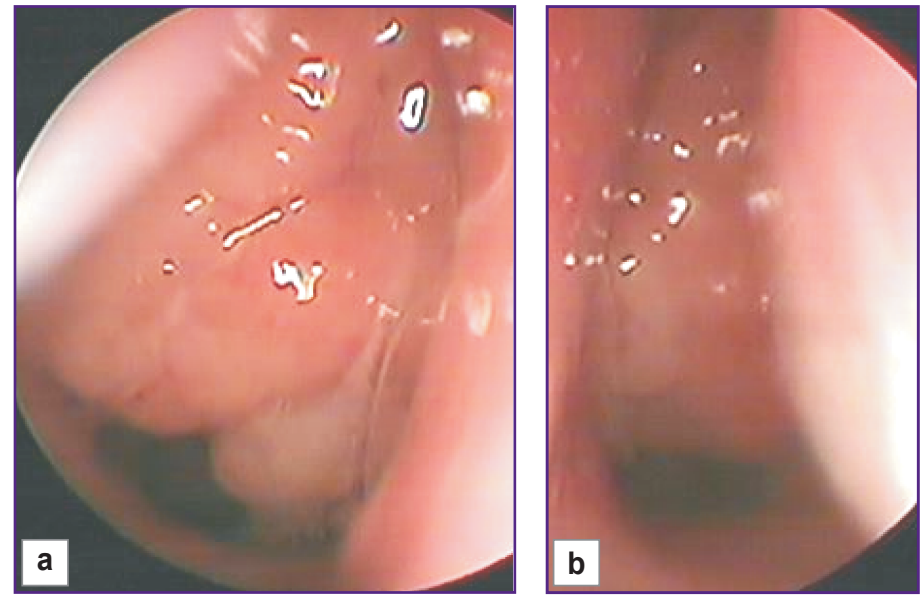

Figure 12. 12-year-old female patient Ya. Nasal videoendoscopy fragments. Diagnosis: controlled atopic bronchial asthma, moderately severe; persistent perennial allergic rhinitis, moderately severe, drug remission; degree III adenoids. Photo: the right (a) and left (b) choanal view; lymphoid tissue of the pharyngeal tonsil closes $2 / 3$ of the choanal lumen
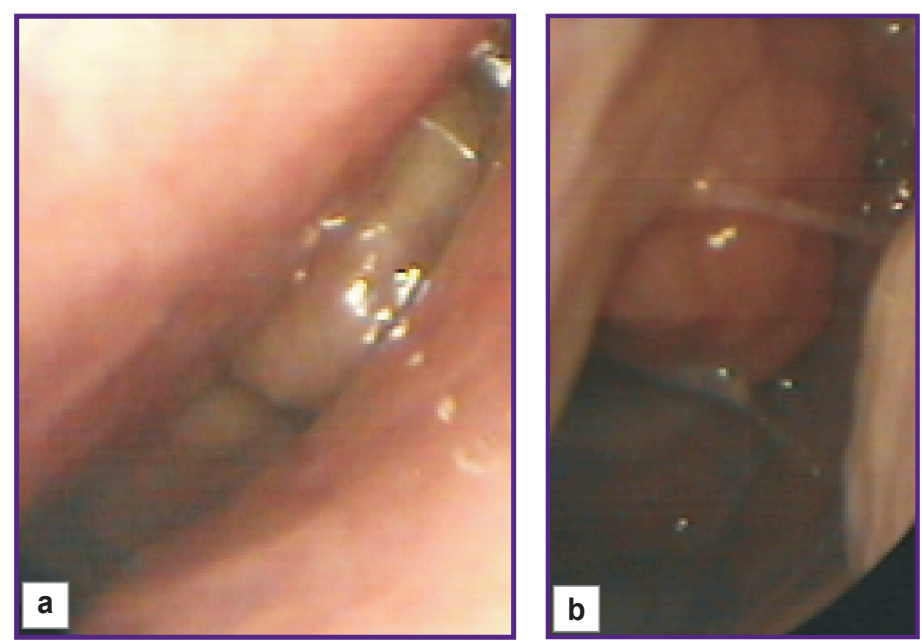

Figure 13. 16-year-old patient R. Nasal videoendoscopy fragments. Diagnosis: atopic bronchial asthma, severe course; persistent allergic rhinitis, severe course; polypous rhinosinusitis; degree I-II adenoids. Photo: the nasal cavity view: the left view, polypous hyperplasia of middle nasal conchal mucosa, middle nasal concha is in contact with the deviated cartilaginous part of the nasal septum (a); lymphoid tissue of the pharyngeal tonsil is visualized in the choanal lumen, it closes over $1 / 3$ of the choanal lumen, the tonsil surface has mucous discharge (b)

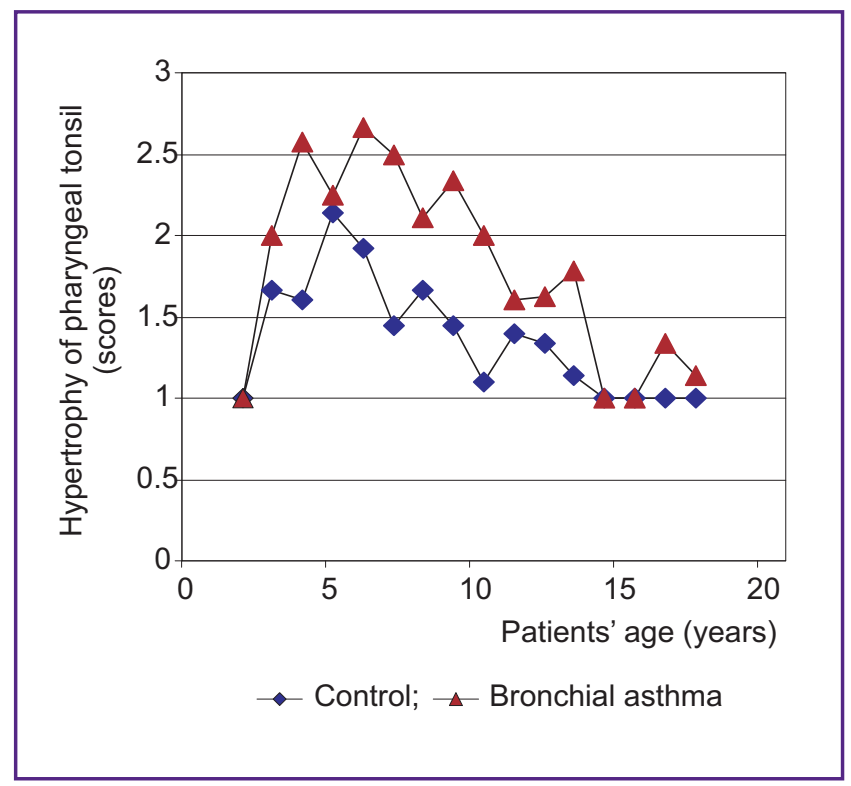

Figure 14. The dependence of pharyngeal tonsil size on age of children with BA. 1 point: no hypertrophy of pharyngeal tonsil (HPT 0- I degree); 2 points: II degree HPT; 3 points: III degree HPT control children. The analysis of age composition showed HPT to be more typical for preschool and primary school children both in BA patients and controls; however, in all age periods the size of pharyngeal tonsil in BA patients was larger than in children with no BA diagnosis. Nasal videoendoscopy enabled to state HPT preservation in a significant part of children (in BA children of grammar school age group: $45.8 \%$, and even among some adolescents), as shows Figure 14.

The differences in pharyngeal tonsil condition in children with BA and controls were found in all age groups: among preschool children: $\chi^{2}=13.3$; $p=0.0013$; in primary school children: $\chi^{2}=16.2 ; p<0.0003$; in grammar school children: $\chi^{2}=7.5 ; p<0.02$. HPT was revealed neither in adolescents nor in controls, while 4 adolescents with BA were found to have degree II HPT.

Nasal videoendoscopy findings proved the relationship between HPT and age both in the control group (children without BA), and also in patients with BA (See the Table). However, in general, children with BA in all age groups were characterized by higher HPT degree compared to the controls. 
Pharyngeal tonsil condition in children of different age groups with and without bronchial asthma

\begin{tabular}{|c|c|c|c|c|c|c|}
\hline \multirow{3}{*}{ Age } & \multicolumn{6}{|c|}{ Pharyngeal tonsil (hypertrophy) } \\
\hline & \multicolumn{2}{|c|}{$0-$ I degree (norm) } & \multicolumn{2}{|c|}{ Il degree } & \multicolumn{2}{|c|}{ III degree } \\
\hline & abs. number & $\%$ & abs. number & $\%$ & abs. number & $\%$ \\
\hline \multicolumn{7}{|c|}{ Children with bronchial asthma $\left(\chi^{2}=34.3 ; p<0.00001\right)$} \\
\hline Preschool age $(n=36)$ & 5 & 13.9 & 11 & 30.6 & 20 & 55.5 \\
\hline Primary school age $(n=35)$ & 9 & 25.8 & 13 & 37.1 & 13 & 37.1 \\
\hline Grammar school age $(n=24)$ & 13 & 54.2 & 6 & 25.0 & 5 & 20.8 \\
\hline Adolescence $(n=21)$ & 17 & 81.0 & 4 & 19.0 & 0 & 0.0 \\
\hline Total $(n=116)$ & 44 & 37.9 & 34 & 29.3 & 38 & 32.7 \\
\hline \multicolumn{7}{|c|}{ Children without bronchial asthma $\left(\chi^{2}=19.6 ; p<0.003\right)$} \\
\hline Preschool age $(n=34)$ & 16 & 47.1 & 12 & 35.3 & 6 & 17.6 \\
\hline Primary school age $(n=39)$ & 28 & 71.8 & 7 & 20.0 & 4 & 10.2 \\
\hline Grammar school age $(n=20)$ & 18 & 90.0 & 2 & 10.0 & 0 & 0.0 \\
\hline Adolescence $(n=15)$ & 15 & 100.0 & 0 & 0.0 & 0 & 0.0 \\
\hline Total $(n=108)$ & 77 & 71.3 & 21 & 19.4 & 10 & 9.3 \\
\hline
\end{tabular}

Conclusion. Hypertrophy of pharyngeal tonsils makes a considerable contribution to nasal obstruction formation in children with bronchial asthma that requires accurate data on adenoid tissue to develop optimal therapeutic programs. Nasal videoendoscopy enables to eliminate diagnostic difficulties and assess objectively a pharyngeal tonsil condition in patients with bronchial asthma of different age. The merit of nasal videoendoscopy is in obtaining new data that hypertrophy of pharyngeal tonsil is generally more common among patients with asthma compared to those without the disease, and it should be taken into consideration when managing such patients.

Study Funding and Conflicts of Interest. The study was not funded by any sources, and the authors have no conflicts of interest related to the present study.

\section{References}

1. Borzov E.V. Adenoidy $i$ adenoidity $u$ detey [Adenoids and adenoiditis in children]. Moscow: GEOTAR-Media; 2011.

2. Evcimik M.F., Dogru M., Cirik A.A., Nepesov M.I. Adenoid hypertrophy in children with allergic disease and influential factors. Int J Pediatr Otorhinolaryngol 2015; 79(5): 694-697, http://dx.doi.org/10.1016/j.ijporl.2015.02.017.

3. Nuhoglu C., Nuhoglu Y., Bankaoglu M., Ceran O. A retrospective analysis of adenoidal size in children with allergic rhinitis and nonallergic idiopathic rhinitis. Asian Pac J Allergy Immunol 2010; 28(2-3): 136-140.

4. Matveeva A.Yu., Zaitseva O.V., Samsygina G.A., Bogomilsky R.M. Adenoids and bronchial asthma in children - role of local therapy. Pediatriya. Zhurnal im. G.N. Speranskogo 2005; 84(3): 48-53.

5. Grossman J. One airway, one disease. Chest 1997;
111(2 Suppl): 11S-16S, http://dx.doi.org/10.1378/chest.111.2_ supplement.11s.

6. Bykova V.P., Bruevich O.V., Pakina V.R., Payushina O.V. Adenoids as an inductive organ of mucosal immunity of upper respiratory tract. Rossiyskaya rinologiya 2005; 2: 175-176.

7. Brandtzaeg P. Immune functions of nasopharyngeal lymphoid tissue. Adv Otorhinolaryngol 2011; 72: 20-24, http:// dx.doi.org/10.1159/000324588.

8. Bykova V.P. Structural principles of mucosal immunity of upper respiratory tract. Rossiyskaya rinologiya 1999; 1 : 5-9.

9. Krasilnikova S.V., Eliseeva T.I., Shakhov A.V., Prakhov A.V., Balabolkin I.I. Video endoscopic method of estimation state of nasal and pharyngonasal cavity in children with bronchial asthma. Sovremennye tehnologii $v$ medicine 2012; 3: 41-45.

10. Modrzynski M., Zawisza E. An analysis of the incidence of adenoid hypertrophy in allergic children. Int J Pediatr Otorhinolaryngol 2007; 71(5): 713-719, http://dx.doi. org/10.1016/j.jporl.2006.12.018.

11. Pagella F., De Amici M., Pusateri A., Tinelli G., Matti E., Benazzo M., Licari A., Nigrisoli S., Quaglini S., Ciprandi G., Marseglia G.L. Adenoids and clinical symptoms: epidemiology of a cohort of 795 pediatric patients. Int J Pediatr Otorhinolaryngol 2015; 79(12): 2137-2141, http://dx.doi. org/10.1016/j.ijporl.2015.09.035.

12. Sadeghi-Shabestari M., Jabbari Moghaddam Y., Ghaharri $H$. Is there any correlation between allergy and adenotonsillar tissue hypertrophy? Int J Pediatr Otorhinolaryngol 2011; 75(4): 589-591, http://dx.doi. org/10.1016/j.ijporl.2011.01.026.

13. Karpova E., Sokolova M., Pampura A. Influence of adenotomy on the quality of life of children with association of bronchial asthma and allergic rhinitis. Rossiyskaya rinologiya 2007; 1: 39-42. 
14. Pukhlik S.M., Nevert E.G., Karpovich D.V. Adenoids and allergic rhinitis. Novosti meditsiny i farmatsii 2011; 380.

15. Zhang L., Mendoza-Sassi R.A., César J.A., Chadha N.K. Intranasal corticosteroids for nasal airway obstruction in children with moderate to severe adenoidal hypertrophy. Cochrane Database Syst Rev 2008; 3: CD006286, http://dx.doi. org/10.1002/14651858.CD006286.pub2.

16. Anfuso A., Ramadan $H_{\text {., }}$, Terrell A., Demirdag $Y$., Walton C., Skoner D.P., Piedimonte G. Sinus and adenoid inflammation in children with chronic rhinosinusitis and asthma. Ann Allergy Asthma Immunol 2015; 114(2): 103-110, http:// dx.doi.org/10.1016/j.anai.2014.10.024.

17. Undem B.J., McAlexander M., Hunter D.D. Neurobiology of the upper and lower airways. Allergy 1999; 54 (Suppl 57): 81-93, http://dx.doi.org/10.1111/j.1398-9995.1999. tb04409.x.

18. Braunstahl G.J. United airways concept: what does it teach us about systemic inflammation in airways disease? Proc Am Thorac Soc 2009; 6(8): 652-654, http://dx.doi.org/10.1513/ pats.200906-052DP.

19. Passali D., Benedetto de F., Benedetto de M., Chiaravalloti F., Damiani V., Passali F.M., Bellussi L.M.; Working Group. Rhino-Bronchial Syndrome. The SIO-AIMAR (Italian Society of Otorhinolaryngology, Head Neck SurgeryInterdisciplinary Scientific Association for the Study of the Respiratory Diseases) survey. Acta Otorhinolaryngol Ital 2011; 31(1): 27-34.

20. Saedi B., Sadeghi M., Mojtahed M., Mahboubi H. Diagnostic efficacy of different methods in the assessment of adenoid hypertrophy. Am J Otolaryngol 2011; 32(2): 147-151, http://dx.doi.org/10.1016/j.amjoto.2009.11.003.

21. Natsional'naya programma "Bronkhial'naya astma $u$ detey. Strategiya lecheniya i profilaktika" [National program "Bronchial asthma in children. Treatment strategy and prevention"]. Moscow; 2012.

22. GINA, Global Strategy for Asthma Management and Prevention. 2015. URL: http://www.ginasthma.org.

23. Mezhdunarodnaya statisticheskaya klassifikatsiya bolezney i problem, svyazannykh so zdorov'em Desyatogo peresmotra (MKB-10) [International Statistical Classification of Diseases and Related Health Problems 10th Revision (ICD10)]. 2015. URL: http://мкб11.pq.

24. Bousquet J., Schünemann H.J., Samolinski B., Demoly P., Baena-Cagnani C.E., Bachert C., Bonini S., Boulet L.P., Bousquet P.J., Brozek J.L., Canonica G.W., Casale T.B., Cruz A.A., Fokkens W.J., Fonseca J.A., van Wijk R.G., Grouse L., Haahtela T., Khaltaev N., Kuna P., Lockey R.F., Lodrup Carlsen K.C., Mullol J., Naclerio R., O'Hehir R.E., Ohta K., Palkonen S., Papadopoulos N.G., Passalacqua G., Pawankar R., Price D., Ryan D., Simons F.E., Togias A., Williams D., Yorgancioglu A., Yusuf O.M., Aberer W. Adachi M. Agache 1., Aït-Khaled N., Akdis C.A., Andrianarisoa A., Annesi-Maesano I., Ansotegui I.J., Baiardini 1. Bateman E.D. Bedbrook A., Beghé B., Beji M., Bel E.H., Ben Kheder A., Bennoor K.S., Bergmann K.C., Berrissoul F. Bieber T. Bindslev Jensen C., Blaiss M.S., Boner A.L., Bouchard J., Braido F., Brightling C.E., Bush A., Caballero F., Calderon M.A., Calvo M.A., Camargos P.A., Caraballo L.R., Carlsen K.H., Carr W.., Cepeda A.M., Cesario A., Chavannes N.H., Chen Y.Z., Chiriac A.M., Chivato
Pérez T., Chkhartishvili E., Ciprandi G., Costa D.J., Cox L., Custovic A., Dahl R., Darsow U., De Blay F., Deleanu D., Denburg J.A., Devillier P., Didi T., Dokic D., Dolen W.K., Douagui H., Dubakiene R., Durham S.R., Dykewicz M.S., El-Gamal Y., El-Meziane A., Emuzyte R., Fiocchi A., Fletcher M., Fukuda T., Gamkrelidze A., Gereda J.E., González Diaz S., Gotua M., Guzmán M.A., Hellings P.W., Hellquist-Dahl B., Horak F., Hourihane J.O., Howarth P., Humbert M., Ivancevich J.C., Jackson C., Just J., Kalayci O., Kaliner M.A., Kalyoncu A.F., Keil T., Keith P.K., Khayat G., Kim Y.Y., Koffi N'goran B., Koppelman G.H., Kowalski M.L., Kull I., Kvedariene V., Larenas-Linnemann D., Le L.T., Lemière C., Li J., Lieberman P., Lipworth B., Mahboub B., Makela M.J., Martin F., Marshall G.D., Martinez F.D., Masjedi M.R., Maurer M., Mavale-Manuel S., Mazon A., Melen E., Meltzer E.O., Mendez N.H., Merk H., Mihaltan F., Mohammad Y., Morais-Almeida M., Muraro A., Nafti S., Namazova-Baranova L., Nekam K., Neou A., Niggemann B., Nizankowska-Mogilnicka E., Nyembue T.D., Okamoto Y., Okubo K., Orru M.P., Ouedraogo S., Ozdemir C., Panzner P., Pali-Schöll I., Park H.S., Pigearias B., Pohl W., Popov T.A., Postma D.S., Potter P., Rabe K.F., Ratomaharo J., Reitamo S., Ring J., Roberts R., Rogala B., Romano A., Roman Rodriguez M., Rosado-Pinto J., Rosenwasser L., Rottem M., Sanchez-Borges M., Scadding G.K., Schmid-Grendelmeier P., Sheikh A., Sisul J.C., Solé D., Sooronbaev T., Spicak V., Spranger O., Stein R.T., Stoloff S.W., Sunyer J., Szczeklik A., Todo-Bom A., Toskala E., Tremblay Y., Valenta R., Valero A.L., Valeyre D., Valiulis A., Valovirta E., Van Cauwenberge P., Vandenplas O., van Weel C., Vichyanond P., Viegi G., Wang D.Y., Wickman M., Wöhrl S., Wright J., Yawn B.P., Yiallouros P.K., Zar H.J., Zernotti M.E., Zhong N., Zidarn M., Zuberbier T., Burney P.G., Johnston S.L., Warner J.O.; World Health Organization Collaborating Center for Asthma and Rhinitis. Allergic Rhinitis and its Impact on Asthma (ARIA): achievements in 10 years and future needs. J Allergy Clin Immunol 2012; 130(5): 1049-1062, http://dx.doi. org/10.1016/j.jaci.2012.07.053.

25. International Consensus Report on the diagnosis and management of rhinitis. International Rhinitis Management Working Group. Allergy 1994; 49(19 Suppl): 1-34.

26. Fokkens W.J., Lund V.J., Mullol J., Bachert C., Alobid I., Baroody F., Cohen N., Cervin A., Douglas R., Gevaert P., Georgalas C., Goossens H., Harvey R., Hellings P., Hopkins C., Jones N., Joos G., Kalogjera L., Kern B., Kowalski M., Price D., Riechelmann H., Schlosser R., Senior B., Thomas M., Toskala E., Voegels R., Wang de Y., Wormald P.J. EPOS 2012: European position paper on rhinosinusitis and nasal polyps 2012. A summary for otorhinolaryngologists. Rhinology 2012; 50(1): 1-12.

27. Bogomil'skiy M.R., Chistyakova V.R. Detskaya otorinolaringologiya [Pediatric otorhinolaryngology]. Moscow: GEOTAR-Media; 2012.

28. Wang D., Clement P., Kaufman L., Derde M.P. Fiberoptic examination of the nasal cavity and nasopharynx in children. Int J Pediatr Otorhinolaryngol 1992; 24(1): 35-44, http://dx.doi.org/10.1016/0165-5876(92)90064-v.

29. RADAR. Allergicheskiy rinit u detey: rekomendatsii $i$ algoritm pri detskom allergicheskom rinite [RAPAR. Allergic rhinitis in children: recommendations and algorithm in pediatric allergic rhinitis]. Moscow: Original-maket; 2015. 